\title{
ATIVAÇÃO EM CASA: PRINCÍPIOS DE ATIVAÇÃO COMPORTAMENTAL PARA MINIMIZAÇÃO DOS EFEITOS DO ISOLAMENTO SOCIAL
}

\author{
ACTIVATION AT HOME: PRINCIPLES OF BEHAVIORAL ACTIVATION TO MINIMIZE THE \\ EFFECTS OF SOCIAL ISOLATION
}

\section{ACTIVACIÓN EN CASA: PRINCIPIOS DE ACTIVACIÓN CONDUCTUAL PARA MINIMIZAR LOS EFECTOS DEL AISLAMIENTO SOCIAL.}

\author{
EDUARDO SOUSA GOTTI ${ }^{1}$ - ORCID 0000-0002-2363-7114 \\ JOÃO GABRIEL FERREIRA ARGONDIZZI ${ }^{1}$ - ORCID 0000-0001-8362-0085 \\ NICOLLE ESSELIN LAZARINI FAZOLINO ${ }^{1}$ - ORCID 0000-0002-0094-9350 \\ MARIANA DIAS DOS SANTOS ${ }^{1}$ - ORCID 0000-0001-6701-8297 \\ JÚLIA LUCIULA SILVA ${ }^{1}$ - ORCID 0000-0001-5484-8603 \\ ELIMAR ADRIANA DE OLIVEIRA ${ }^{1}$ - ORCID 0000-0002-5750-7764 \\ ROBERTO ALVES BANACO² - ORCID 0000-0002-0619-338X \\ ${ }^{1}$ UnIVERSIDADE FEDERAL DO TRIÂNGULO MINEIRO \\ ${ }^{2}$ AssociaÇÃo PARADIGMA - CENTRO DE CIÊNCIAS E TECNOLOGIA DO COMPORTAMENTO
}

\section{RESUMO}

A quarentena e o isolamento social são medidas sanitárias profiláticas para retardar o avanço de pandemias como a COVID-19. Contudo, essas medidas podem impactar negativamente a saúde mental das pessoas dificultando a adesão destas às recomendações das agências de saúde. A partir disso, o site "Ativação em Casa" é baseado em princípios da Ativação Comportamental que objetiva auxiliar as pessoas na construção de rotinas proativas, produtivas e prazerosas, aumentando as chances de cooperarem com as medidas sanitárias ao ficarem em casa.

Palavras-chave: Ativação Comportamental; Quarentena; Pandemia; Análise do Comportamento.

\section{ABSTRACT}

Quarantine and social isolation are prophylactic health measures to delay the advance of pandemics such as COVID-19. However, these measures can negatively impact people's mental health, making it difficult for them to adhere to the recommendations of health agencies. From that, the "Ativação em Casa" (Activation at Home, in English) website is based on Behavioral Activation principles, which aims to assist people in the constructing proactive, productive, and pleasurable routines, increasing the chances of cooperating with health measures when staying at home.

Keywords: Behavioral Activation; Quarantine; Pandemic; Behavior Analysis.

\section{RESUMEN}

La cuarentena y el aislamiento social son medidas profilácticas de salud para retrasar el avanzo de pandemias como la COVID-19. Sin embargo, estas medidas pueden afectar negativamente la salud mental de las personas, lo que les dificulta cumplir con las recomendaciones de las agencias de salud. Las medidas que minimizan estos daños y que aumentan la cooperación de las personas para quedarse en casa son de importancia fundamental. En base a esto, el sitio web "Ativação em Casa" (Activación en Casa, en español) se basa en los principios de Activación conductual, que tiene como objetivo ayudar a las personas en la construcción de rutinas proactivas, productivas y placenteras, aumentando las posibilidades de cooperar con las medidas de salud cuando se quedan en casa.

Palabras-clave: Activación Conductual; Cuarentena; Pandemia; Análisis de la conducta.

\footnotetext{
Os autores agradecem a agência de fomento do projeto de extensão no edital PROEXT/FUNEPU No 03/2020/DDEX/PROEXT: Fundação de Ensino e Pesquisa de Uberaba (FUNEPU) e à Pró-Reitoria de Extensão da Universidade Federal do Triângulo Mineiro. Correspondência para: Eduardo Sousa Gotti. E-mail: sousagottieduardo9@gmail.com
}

DOI: http://dx.doi.org/10.18542/rebac.v16i1.9096 


\section{MEDIDAS SANITÁRIAS NO COMBATE À COVID-} 19 E IMPACTOS NA SAÚDE MENTAL

A pandemia de COVID-19 causada pelo coronavírus (SARS-CoV-2) tem sido diagnosticada em mais de dez milhões de pessoas e registrado mais de 500 mil mortes em todo mundo até a data de 29 de junho de 2020 , com tendência segura de aumentar nos próximos meses. Diante desse quadro calamitoso, que cada vez avança mais sobre todas as partes do mundo, são inúmeros os países que, afetados pelo surto, têm adotado medidas para conter a disseminação e, assim, possibilitar que os seus sistemas de saúde deem conta da elevada sobrecarga dos serviços que a doença demanda.

Dentre as medidas adotadas, estão a quarentena e $o$ isolamento social. A quarentena consiste em uma medida pontual, volta a pessoas infectadas ou que tiveram contato com pessoas infectadas. $\mathrm{O}$ isolamento social é uma medida generalizada. Tanto as pessoas potencialmente infectadas quanto as plenamente livres de infecção devem fazer o isolamento para reduzir o contato entre as pessoas e, portanto, o contágio, mesmo sem uma avaliação para separação de contaminados e não-contaminados. Entretanto, o público de maneira geral utiliza esses termos de forma intercambiável, sem maiores prejuízos práticos na orientação das medidas a serem adotadas (Brooks et al., 2020).

Contudo, a quarentena e o isolamento social provocam impactos psicológicos negativos nas pessoas que os vivenciam, sejam pacientes infectados, familiares, cuidadores ou profissionais, tanto os de saúde, quanto os de atividades essenciais (motoristas, entregadores, pessoal de limpeza etc). Como efeito, observaram-se, em outras pandemias, diferentes reações diante dessas medidas sanitárias que variam desde o tédio, irritação, episódios de depressão e ansiedade e sintomas de transtornos póstraumáticos. Esses impactos são tão maiores quanto mais prolongados os períodos de quarentena ou isolamento. Além disso, algumas condições implicam em maiores riscos de impacto destas medidas. Essas condições são: conflitos familiares antecedentes; transtornos psicológicos préexistentes; prejuízos financeiros (gastos com saúde, desemprego, déficits econômicos em função da paralisação dos serviços); pouco acesso a informações adequadas; privação de subsídios básicos para abastecimento (água, comida, energia, remédios); redes sociais empobrecidas; baixa disponibilidade de atividade de lazer (Brooks et al., 2020; Huremovic, 2019; Rajkumar, 2020).

Os impactos psicológicos negativos provocados pela quarentena e isolamento social são amplos, substanciais e duradouros. Isso não significa que essas medidas não devam ser adotadas, pois os riscos decorrentes da proliferação da doença são maiores (Brooks et al., 2020). Contudo, se a quarentena e o isolamento social são essenciais, é preciso considerar medidas que as tornem mais toleráveis e o menos danosa possível. Há medidas com potencial para mitigar o desconforto que podem não apenas prevenir o aparecimento de comportamentos característicos de transtornos de humor e transtornos de estresse agudo ou crônico, como também aumentar o engajamento à própria medida de quarentena e isolamento, e que tem por consequência um ganho social pelo retardamento da disseminação da doença pela população. Nesse sentido, estratégias que atendam a esse fim são fundamentais para o enfrentamento da COVID-19.

Essas estratégias são variadas, abrangendo medidas possíveis de serem adotadas por autoridades de saúde, comunidades, lideranças locais e indivíduos. São elas: informar de maneira clara sobre os dados de saúde pública; garantir suprimentos básicos (água, medicamentos, comida, energia), dar ênfase ao altruísmo e experiências positivas e, além disso, fornece atividades potencialmente gratificantes para que as pessoas possam se engajar durante a quarentena e isolamento (Brooks et al., 2020). As atividades gratificantes que podem ser realizadas em casa contrastam com as medidas que são aversivas que geralmente são prescritas, tais como: sair de máscara para evitar a contaminação, usar álcool gel - medidas estas que sinalizam o tempo todo comportamentos de esquiva - que perdem a força no decorrer do tempo em que o aversivo não acontece - e que aumentam o desconforto inclusive para a realização de atividades básicas fora de casa, nas condições em que se faz necessário sair dela.

Para as pessoas que experimentam a quarentena ou isolamento social, pode ser particularmente difícil lidar com uma vida na qual, de forma drástica e inesperada, lhes foi restringido o contato social, privadas de suas atividades de lazer, desorganizando sua rotina de trabalho, tolhendo a sua liberdade pessoal de transitar, ameaçando as suas finanças, o sustento pessoal e de sua família, além dos próprios riscos da doença que justificam a medida sanitária. A partir de uma leitura teórica comportamentalista, que busca compreender a relação entre organismos e seus ambientes, entende-se que esses eventos ocorridos na vida dessas pessoas são eventos aversivos - e estressores, portanto - nos quais predominam relações coercitivas do controle de seu comportamento de se manter cativo em casa. É comum que, nessas circunstâncias, um dos efeitos emocionais provocados seja irritação, frustração, ansiedade e tristeza.

Esses estados emocionais observados são decorrentes da mudança no ambiente da população geral e podem se estender por longo período se as pessoas a eles expostos não dispuserem de variabilidade comportamental para acessar novas fontes de interação prazerosa e potencialmente gratificante. Estudos experimentais apontam que situações de estresse crônico podem gerar, além dessas condições emocionais, uma mais grave que compõe o quadro de depressão, que é a anedonia. Os dados são advindos da literatura sobre o Estresse Crônico Moderado (CMS) e estão bem estabelecidos na literatura (Willner, Towell, Sampson, Sophoklcous, \& Muscat, 1987; Thomaz, 2001; Oliveira, 2009). Durante a exposição a um protocolo de estressores, continuada e aleatoriamente, ou seja, sem controle e sem previsibilidade sobre eles, os eventos do mundo que funcionaram até então como reforçadores perdem sua capacidade reforçadora. Isto resulta, gradativamente, em indivíduos apáticos a esses eventos (por estarem em um estado denominado por "anedonia"). Esse estado vai se instalando aos poucos e, 
quando o protocolo de estressores é suspenso, não é revertida a condição dos organismos experimentais. Eles permanecem anedônicos. Porém, as pesquisas também afirmam que se o comportamento operante positivamente reforçado for mantido durante a submissão ao protocolo de estressores, o estado de anedonia, se acontecer, acontecerá mais tarde e, quando os estressores são suspensos, a condição de voltar a ser reforçado se instaura rapidamente (para maiores detalhes veja Banaco, Zamignani, Costa, \& Dantas, 2015).

\section{ATIVAÇÃO COMPORTAMENTAL PARA MINIMIZAR OS IMPACTOS DAS MEDIDAS SANITÁRIAS}

Umas das formas de combater esse estado emocional é um conjunto de técnicas comportamentais chamado Ativação Comportamental (AC). A AC, grosso modo, pode ser resumida em três domínios de intervenção: 1) enriquecimento de agenda de atividades prazerosas; 2) enfrentamento das condições que são fontes de estimulação aversiva e 3) resolução de problemas (Kanter, Busch, \& Rusch, 2009; Kanter et al., 2010; Martell, Dimidjian, \& Herman-Dunn, 2010).

Essa técnica foi desenvolvida a partir da década de 60 , por C. B. Ferster, baseado nos escritos de B. F. Skinner e da descrição da depressão advinda da literatura cognitivista (Beck, 1967). Ferster (1973) descreveu, em processos comportamentais, como a depressão poderia ser instalada e como ela poderia ser tratada. Essa descrição se tornou uma técnica que desfruta hoje de evidências de eficácia no tratamento da depressão e conta atualmente com aplicativos virtuais que facilitam a sua implementação prática mesmo que remotamente: a Ativação Comportamental.

Ela está baseada na observação de que ações das pessoas que deixam de produzir reforçadores produzem um estado de depressão, conforme já apontado neste texto. Também está baseada na observação de que eventos aversivos incontroláveis e imprevisíveis produzem o mesmo estado (Ferreira \& Tourinho, 2013). Por esta razão, os dois pilares que sustentam a Ativação Comportamental procuram reinstalar os repertórios que foram minguando por falta de reforçadores ou pela quebra de contingência entre ações e reforçadores (ausência de controle por extinção do tipo I e II, Catania, 1999), e também procura instalar ou reinstalar o repertório de solução de problemas (eliminar a imprevisibilidade).

A Ativação Comportamental, desde sua proposição inicial, passou por várias transformações e se desenvolveu em várias ramificações, nem sempre com inspiração totalmente analítico-comportamental (para acessar esta história, veja Kanter, Busch, \& Rush, 2009).

Nos dias atuais, essa modalidade terapêutica também tem sido praticada em formatos de teleterapia com eficácia similar àquelas realizadas presencialmente (Lazzari, Egan, \& Rees, 2011; Dahne et al., 2017). Entretanto, destaca-se que a produção em torno dessa técnica é predominantemente voltada para interações sociais em contextos extradomiciliares. Isso não significa que os seus protocolos não possam ser adaptados para a realidade de pessoas que estão confinadas em suas casas em função das medidas sanitárias de quarentena e isolamento social. Destaca-se ainda que resultados de meta-análises recentes têm sugerido a eficácia da Ativação Comportamental para além do tratamento da depressão, abrangendo também o tratamento de sintomas de ansiedade (Stein, Carl, Cuijpers, Karyotaki, \& Smits, 2020). A aplicação desses seus princípios terapêuticos pode ser particularmente útil para um cenário da pandemia no qual as pessoas ficaram mais ansiosas (Brooks et al., 2020). Uma orientação geral necessária para a área de saúde mental é verificar quais intervenções baseadas em evidências podem ser rapidamente reajustadas em escala para a pandemia da COVID-19 e identificar as lacunas de intervenções remotas feitas sob medida para aumentar o bem-estar e redução dos problemas enfrentados (Holmes et al., 2020).

Assim, de forma virtual e remotamente, poderia ser desenvolvido um extenso rol de dicas de interações que as pessoas possam realizar em seu dia-a-dia durante o período de confinamento. Essas dicas seriam como a lista de atividades prazerosas, desenvolvida por Lewinsohn (Lewinsohn \& Graf, 1973), que serve na orientação e estruturação de uma agenda enriquecida de atividades que tenham efeitos antidepressivos. A reorganização da rotina para a nova realidade pode ser facilitada. Desta feita, reduziria os riscos de que as pessoas fiquem expostas à própria sorte na realização de atividades gratificantes que, de maneira geral, ocorrem esporadicamente, dando brechas para crescentes momentos de tédio e irritação. Em síntese, o que é proposto neste artigo é o uso da Ativação Comportamental para a depressão no contexto doméstico com finalidade de redução do impacto negativo da quarentena e isolamento social.

Para isso, esse rol de atividades, que poderiam ser desenvolvidas, abrangeria um extenso conjunto de práticas sociais das pessoas (trabalho, lazer, religião/espiritualidade, relacionamentos, ajudas humanitárias, dentre outros), agora adaptadas para serem realizadas no espaço da casa. A proposta do artigo consiste em fazer um levantamento dessas atividades, abrangendo diferentes faixas etárias (crianças, adolescentes, adultos e idosos) e disponibilizá-las em um site que foi desenvolvido para os fins de promover rotinas ativas, agradáveis e com potencial gratificação pessoal para as pessoas em quarentena e isolamento.

Nesse sentido, é preciso destacar que a Ativação Comportamental é utilizada para fins distintos ao inicialmente proposto que seria o seu emprego enquanto recurso terapêutico no tratamento da depressão já instalada. $\mathrm{O}$ uso proposto aqui é profilático. Contudo, apesar dessas distinções dos usos, ambos confluem para um entendimento comum que é o cultivo de variedade de repertórios para acessar, por meio de comportamentos, variadas fontes de reforçamento como uma inoculação contra a depressão (Banaco et al., 2005; Cavalcante, 1997). Outra diferença diz respeito a que a Ativação Comportamental se desenvolveu dentro de uma tradição clínica de sujeitos como seu próprio controle, mas, como apontou Sidman (2006), ao falar sobre o alcance social que se faz necessário da ciência do comportamental, é preciso "usar de métodos de generalidade mais ampla, no sentido 
de afetar muitas pessoas ao mesmo tempo - ou em curto tempo, sem estarmos necessariamente preocupados com quaisquer membros específicos da população relevante." (p. 285).

A pandemia tem exigido intervenções não apenas em muitas pessoas, mas também em curto tempo. Isso não implica em demérito das condições particulares do formato clínico tradicional. Pelo contrário, justamente em função de seus sucessos é que agora são adaptados para atingir uma parcela maior de pessoas. Afinal:

(...) deve-se reconhecer que os grandes avanços da saúde pública não têm vindo do tratamento de pessoas doentes. Ao contrário, devemos nossos crescentes tempo de vida à libertação das doenças às aplicações da ciência e da engenharia tecnológica em dimensões populacionais: por exemplo, as ciências e técnicas de bacteriologia aplicada, como a sanitização; virologia, como no controle dos vírus por meio de vacinação; engenharia sanitária, como nos esgotos modernos, e em coleta e tratamento de lixo e dejetos; purificação de comida e água, como na descontaminação e dessalinização; e coisas assim. (Sidman, 2006, p. 283)

As mídias sociais desempenham um papel útil para ajudar a compartilhar e disseminar recursos (Huremovic, 2019). Visando ampliar o alcance, baseado em modelos de sites e modelos teleterapêuticos de Ativação Comportamental (Dahne et al., 2017), o site Ativação em Casa disponibilizou à comunidade recursos práticos para enfrentarem o período de isolamento social e quarentena, reduzindo os impactos negativos deles decorrentes e potencializando interações que sejam reforçadoras e gratificantes. A proposta consiste em sistematizar as atividades para otimizar o seu alcance sobre o público em quarentena e isolamento social, reduzindo não apenas os impactos negativos, mas também os possíveis abandonos da medida sanitária em função da exaustão da espera.

\section{O SITE ATIVAÇÃO EM CASA: UM GUIA PARA O BEM-ESTAR NA QUARENTENA.}

O presente artigo é produto de um projeto de extensão desenvolvido pelo Laboratório de Análise do Comportamento da Universidade Federal do Triângulo Mineiro intitulado "Ativação em casa: recursos comportamentais para minimização dos efeitos do isolamento social". Os objetivos do projeto são: 1) disponibilizar à comunidade, no formato on-line (em site do projeto, página no Facebook e perfil no Instagram), um amplo conjunto de dicas de atividades que podem ser desenvolvidas dentro de casa no contexto da quarentena e que são estendidas a diferentes domínios da vida pessoal (amizades, recreação/lazer, estudos, cuidados da casa, religiosidade/espiritualidade etc.); 2) reduzir os impactos negativos ocasionados pelo isolamento social e quarentena e, com isso, minimizar os riscos do abandono dessas medidas sanitárias; 3) possibilitar um espaço virtual para acolher novas dicas da comunidade e também para cultivar relações positivas e otimistas frente a esse cenário; 4) disponibilizar um espaço de troca de experiências e suporte no planejamento de uma nova rotina proativa que ajude a combater os sentimentos de desesperança, solidão ou desespero que são acentuados diante da pandemia.

O site Ativação em Casa $^{1}$ é um espaço virtual (ver Figura 1) que disponibiliza dicas de atividades em diferentes domínios (educação, lazer/recreação/jogos, atividades físicas, relacionamentos, sexo, ajudas humanitárias, cuidados de casa, amizades, religiosidade/espiritualidade). Essas atividades estão disponíveis para diferentes grupos etários: crianças; adolescentes e adultos; idosos. No grupo etário das crianças, não há atividades nos domínios de relacionamento e sexualidade. O principal objetivo do projeto é disponibilizar uma grande lista de atividades nas quais o usuário possa se engajar

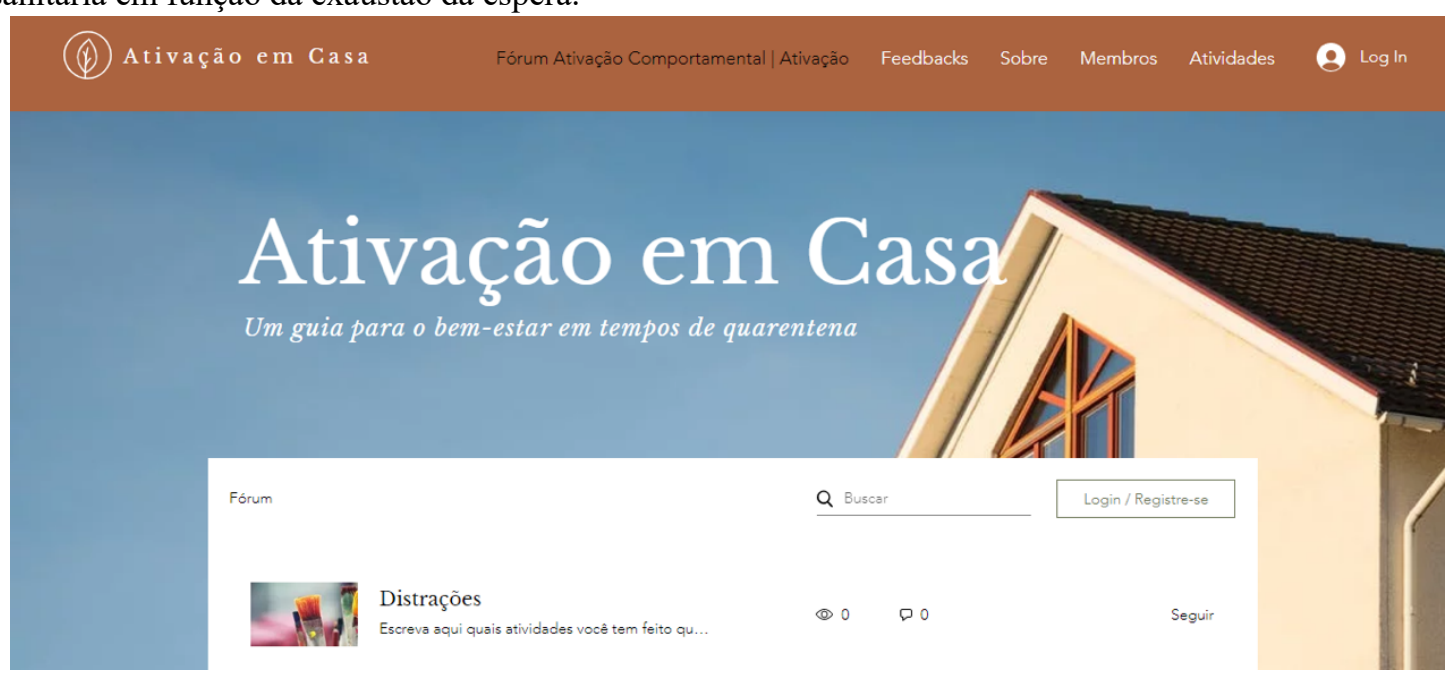

\footnotetext{
${ }^{1}$ Link para acessar o site "Ativação em Casa": https://ativacaocasa.wixsite.com/meusite.
} 
Figura 1. Página do Fórum do site "Ativação em Casa". Nessa página estão disponíveis campos para a comunidade virtual discutir sobre "Distrações"; "Conte boas notícias"; "Atividades mais difíceis", "Dicas para a ativação" e "Agradecimentos".

O site contabiliza um total de 384 atividades, distribuídas nos três grupos etários: "Crianças" (71 atividades); "Adolescentes e Adultos" (168) e "Idosos" (137) e além 5 dicas gerais para organizar a nova rotina com as atividades e 3 dicas para cuidadores de idosos com baixa escolaridade. As atividades propostas para idosos foram também planejadas a partir de adaptações de dicas disponíveis no livro "Viva bem a velhice" (Skinner \& Vaughan, 1985). O critério para a contagem das atividades do site foi contabilizar o número de instruções, dicas e links disponíveis no site de Ativação em Casa.

Essas dicas de atividades conduzem a links que acessam sites de diferentes naturezas relacionadas aos respectivos domínios (ver Figuras 2 e 3). Exemplo: No domínio "Educação" do grupo etário "Adolescentes e Adultos" o usuário pode encontrar links para acessar cursos de idiomas, de fotografia, curso preparatórios para processos seletivos, cursos profissionalizantes.

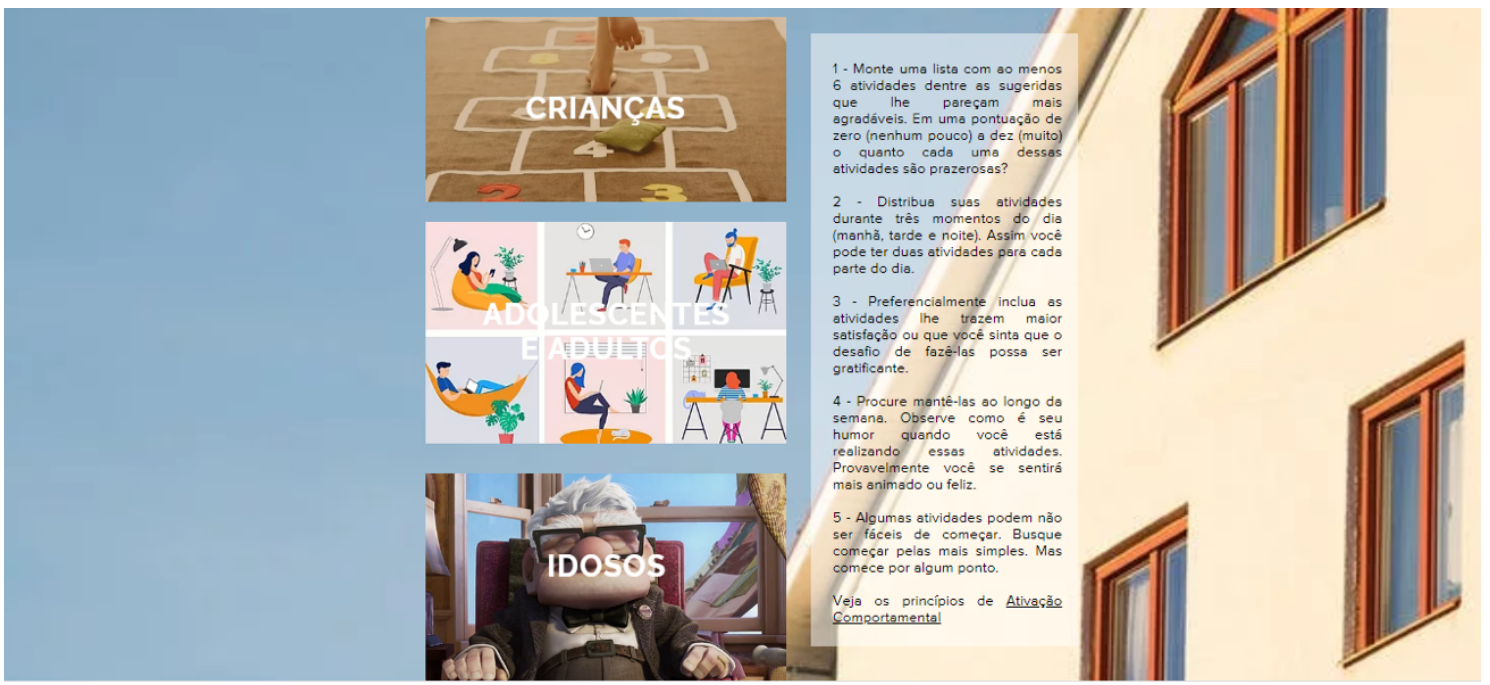

Figura 2. Página no site no qual estão divididos os grupos etários para as quais as atividades em diferentes domínios foram elaboradas: "Crianças"; "Adolescentes e Adultos" e "Idosos".

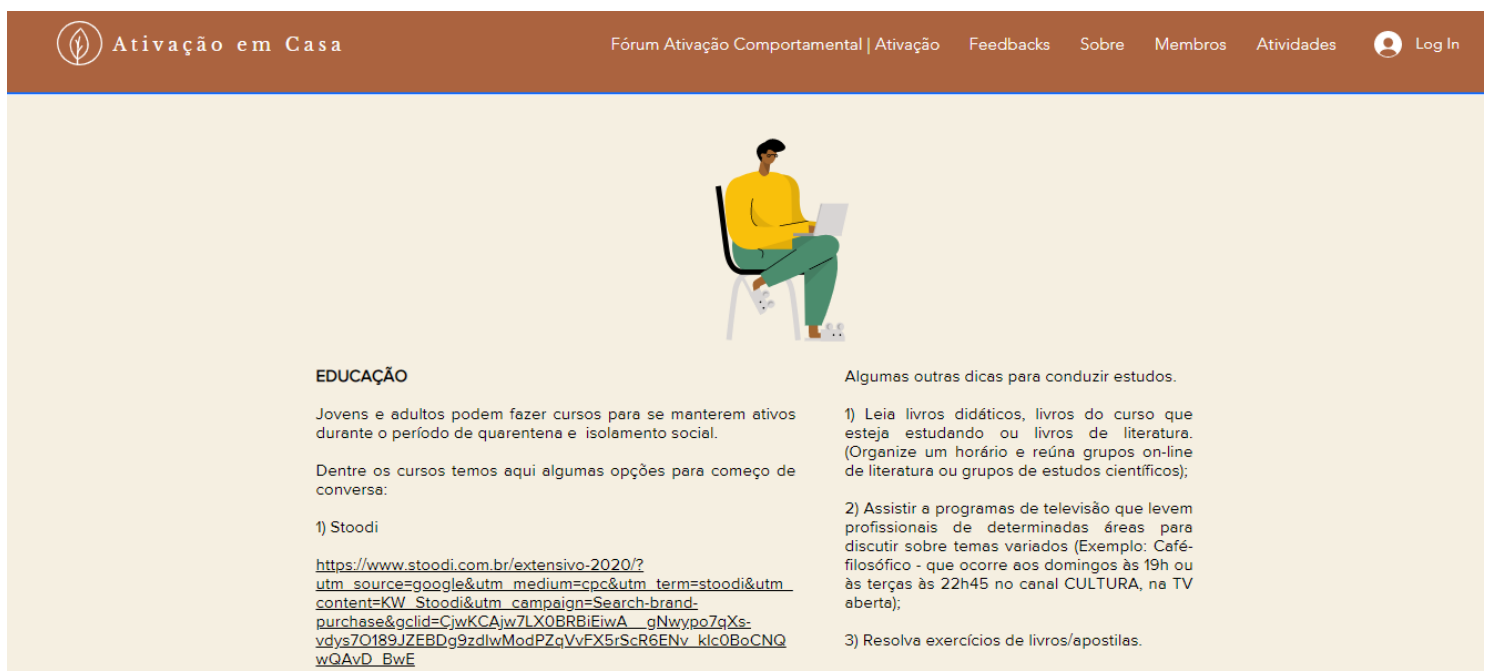

Figura 3. Página de atividades para Adolescentes e Adultos. Nessa parte da imagem estão expostas algumas das dicas encontradas no domínio "Educação".

O objetivo de disponibilizar um amplo rol de opções serve para atender uma diversidade de usuários, sendo acessível a diferentes grupos sociais que possam acessar o site. Assim, esse conjunto de dicas de atividades podem servir como a lista de atividades prazerosas de Lewinsohn, material utilizado para contribuir na estruturação de uma agenda de atividades prazerosas (Martell et al., 2010).

Como forma de avaliar a adesão ao site e às redes sociais, o projeto é monitorado diariamente. Além disso, o site também conta com uma página para feedback (ver Figura 4), na qual há um formulário on-line com perguntas 
e escalas para que as pessoas respondam não apenas o quanto e como o site tem contribuído em suas rotinas, mas para que, de forma orgânica, o site se estruture pela própria experiência dos seus usuários.

É importante destacar que a Ativação Comportamental não se restringe a um inventário de atividades potencialmente agradáveis, mas a um planejamento de um conjunto de intervenções que abrangem enriquecimento de agenda de atividades prazerosas e condições para enfrentamento das fontes de estimulação aversiva.

Contudo, entende-se que a disponibilidade de atividades e instruções claras para a organização de uma rotina mais prazerosa e produtiva pode ser fundamental no atual contexto da quarentena e isolamento social, sobretudo quando se entende que muitas vezes as orientações para lidar com o período de quarentena são abordadas de forma inespecífica ou vaga, tais como: "reinvente seu cotidiano". A ausência de uma descrição operacionalizada que possibilite compreender como o cotidiano será reinventado pode deixar o público à mercê de variações aleatórias e, nesse sentido, o alcance da intervenção ser restrito (Mikulas, 1977). A especificação de comportamentos, tal como a disponibilidade de um "cardápio de opções", para que as pessoas se engajem pode ser preferível a deixá-las sob baixo controle de estímulo que oriente um comportamento adequado. Sobretudo porque a falta de eficiência no controle do estímulo que lhes ajude a fazer uma escolha pode expô-las a condições ansiogênicas. Essas condições, somadas àquelas às quais já estão expostas, tendem a determinar que as pessoas escolham a alternativa impulsiva, o que implica em comportamentos passivos e problemáticos. Isto é, expostos a uma condição aversiva incontrolável, baixo repertório adequado e com poucos controles de estímulos antecedentes efetivos na evocação desses comportamentos adequados, há uma maior probabilidade de as pessoas se engajarem em comportamentos como ruminação de pensamentos pessimistas, consumo excessivo de alimento, álcool ou drogas ou manter-se sedentário, comportamentos estes que produzem reforço imediato.

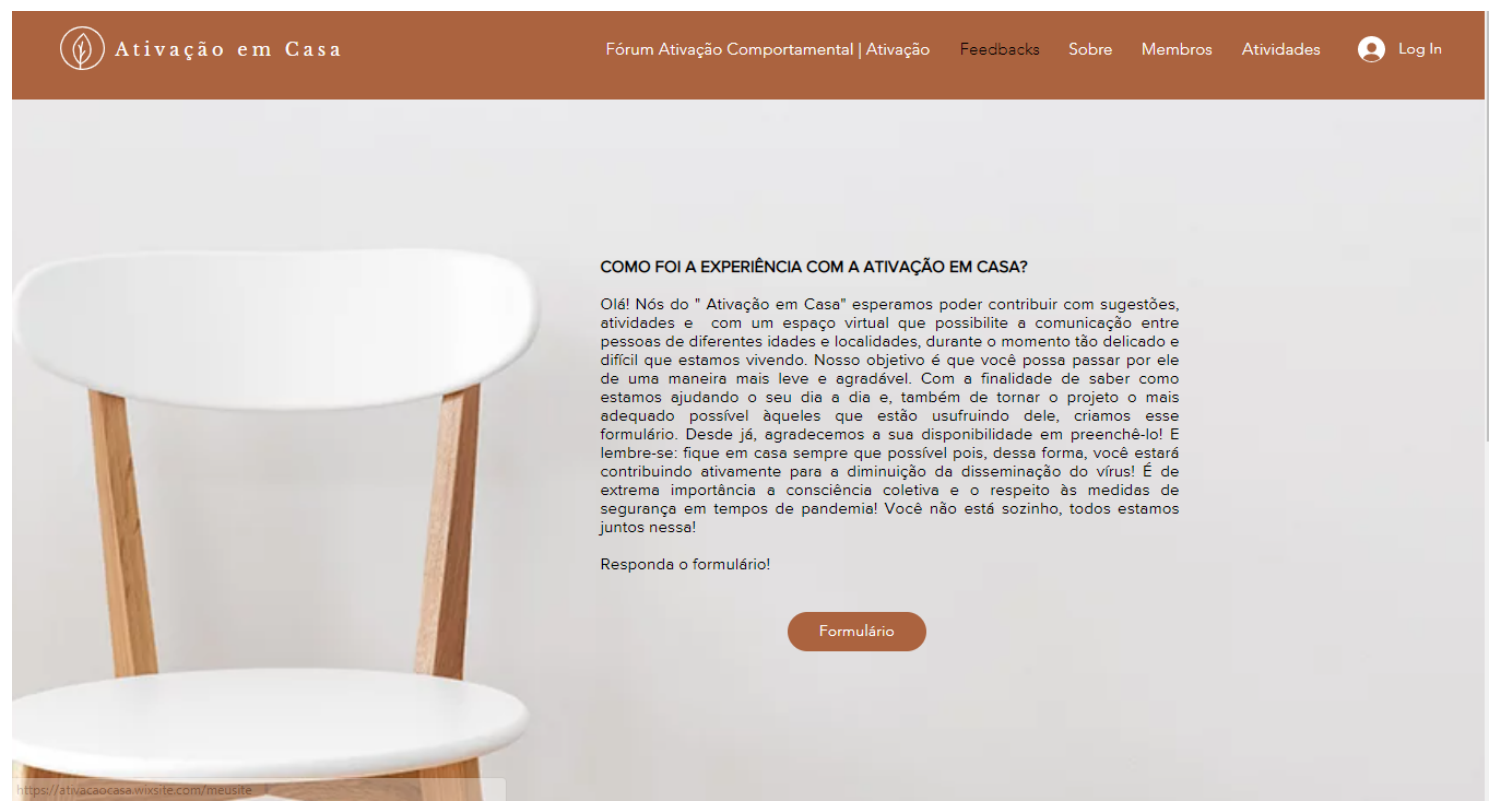

Figura 4. Página no site para acesso ao formulário no qual o usuário pode avaliar o quanto a experiência como site foi útil para a sua estruturação de rotina proativa na quarentena.

"Ficar em casa" também envolve uma recomendação genérica e ampla, haja vista que estar em casa compreende um grande número de comportamentos. Esse amplo conjunto de comportamentos são multideterminados, e são muitas as razões pelas quais as pessoas se mantêm em suas casas ao invés de irem às ruas. Variáveis infraestruturais, econômicas, políticas, culturais e da história de vida pessoal de cada pessoa precisam ser consideradas. O escopo do presente trabalho, contudo, se limita a apresentar uma ferramenta auxiliar na organização de atividades desempenhadas no contexto doméstico para melhor estrutura-las tornando-as mais potencialmente reforçadoras, de maneira que valha a pena ficar em casa.
Considerando a importância de orientar para uma ação proativa, os princípios da ativação comportamental foram adaptados para uma linguagem de mais fácil compreensão para a comunidade em geral, buscando contextualizá-los ao cenário da pandemia.

\section{OS PRINCÍPIOS DE ATIVAÇÃO COMPORTAMENTAL}

Princípio 1: A chave para mudar a forma como as pessoas se sentem é ajudá-las a mudarem o que fazem.

Entende-se que os sentimentos decorrem das interações dos indivíduos com seu ambiente, especialmente o ambiente social. E quando as emoções predominantes são de tristeza, raiva, desânimo ou tédio, é preciso mudar as 
condições do meio para mudar essas emoções. Embora não seja possível retomar as antigas rotinas anteriores à pandemia, é possível estabelecer outras novas e que possam então produzir sensações de maior ânimo e gratificação. Para tanto, é preciso agir, e não esperar que espontaneamente o indivíduo se sinta disposto para agir. Desse modo, pode-se entender que é preciso agir para ter ânimo e não esperar ter ânimo para poder agir. Esperar pode manter a pessoa em um ciclo interminável de tristeza e desânimo. É preciso agir "de fora para dentro" e não de "dentro para fora". Embora essa perspectiva contraste com a visão tradicional de motivação, ela tem papel fundamental no início da mudança de rotina.

Princípio 2: Mudanças na vida podem levar algumas pessoas a um estado mais deprimido e, muitas vezes, elas se envolvem em atividades cujos efeitos imediatos podem mantê-las presas ao longo do tempo em uma condição depressora (exemplos: comer muito, dormir muito, fumar ou fazer consumo de outras drogas).

Diante do contexto da pandemia e as medidas sanitárias profiláticas de isolamento social e quarentena que são necessárias, as pessoas ficam impedidas de emitir muitos dos comportamentos que antes produziam reforçadores (passeios, trabalhos fora de casa, frequentar academias, reuniões entre amigos). Esses comportamentos estão agora em uma condição de suspensão discriminada das contingências de reforço, que experimentalmente é conhecido como time-out, caracterizado por uma remoção das oportunidades do responder (Catania, 1999). Diante dessa nova contingência sinalizada pelas agências de controle como o Ministério da Saúde, as pessoas ficam então restritas aos repertórios que desenvolvem no contexto de suas casas. Considerando que o ritmo das pessoas no trabalho, especialmente em cidades de grande e médio porte, poderia levar com que elas dispendessem extenso tempo fora de casa (Pero \& Stefanelli, 2015), o contato por mais tempo em casa pode ser marcado pela falta de repertório para lidar com esse contexto.

Essa desorganização da rotina pode ser acompanhada de respondentes a grosso modo descritos como ansiedade decorrentes não apenas da perda de reforçadores como a perda de pessoas queridas em função da doença, de parte da mobilidade, bem como também dos prejuízos financeiros envolvendo gastos com a doença ou perda de emprego ou renda. Para lidar com esses estados de humor depressivo que são aversivos em si (Sidman, 2006), as pessoas se engajam em atividades que podem, a princípio e imediatamente, ter o efeito de remover essas emoções tais como o envolvimento com álcool e/ou outras drogas, uso abusivo de jogos, ou dormir longas horas ou ainda ingerir grandes quantidades de calorias. A despeito do alívio imediato que podem proporcionar, esses comportamentos tendem a produzir consequências problemáticas para saúde e que não são apenas mantenedoras da situação problemática como também agravantes, fazendo perpetuar um ciclo de esquiva passiva.

Organizar uma rotina produtiva a partir das bases teóricas da Ativação Comportamental pode ajudar as pessoas a se engajem em atividades, aumentando as chances de ganhos tardios como manutenção da saúde física e minimizando os impactos negativos da quarentena, tais como esses estados emocionais depressivos. Além disso, também poderá dar sequência a um ritmo produtivo, sem procrastinações que poderiam vir a comprometê-lo acadêmica ou financeiramente. As atividades teriam desse modo uma função antidepressiva.

Princípio 3: As pistas para descobrir o que será antidepressivo para uma determinada pessoa estão no que antecede e sucede os comportamentos da pessoa.

Uma pessoa que esteja em sua casa na quarentena, e que passe grande parte de seu tempo deitada no sofá ou em sua cama, pode vir a relatar que está desanimada ou entediada. Caso ela venha a se engajar em uma tarefa nova, como preparar pesos improvisados com garrafas pet e começar a fazer atividades físicas, pode sentir-se animada assim que inicia. Essa mudança de humor decorre da mudança do comportamento. É importante que as pessoas observem que seus estados emocionais podem resultar do que elas fazem. Dado que sua disposição é modificada pelas suas próprias ações, melhor será que ela preencha sua agenda com atividades que, dessa mesma forma, produzam consequências reforçadoras intrínsecas.

Princípio 4: Estruture e programe atividades que sigam um plano, não um estado de espírito.

Desse modo, mesmo sentindo-se desanimado, é preciso agir para manter-se em uma rotina proativa e agradável. Adiar isso significa deixar o próprio bem-estar entregue à sorte de flutuações de humor.

Princípio 5: Mudanças são mais fáceis quando começam por partes pequenas.

Começar uma atividade pode ser um processo penoso quando é extensa e complexa. Possivelmente ela pode ser decomposta em partes menores e mais simples e isso poderá ajudar a iniciá-la. Em estudos sobre esquemas de reforçamento de razão fixa, no qual um número determinado de tarefas é exigido até que se tenha uma gratificação, é comum que ocorram pausas pós-reforço proporcionais ao tamanho da razão (Moreira \& Medeiros, 2019). Esquemas com elevados valores de razão entre número de respostas e número de reforços, nos quais uma série atividades são necessárias e envolvem um elevado custo de resposta, podem ter sua inicialização postergada (Ferster, Culbertson, \& Perrot-Boren, 1982).

Depois de longa série de respostas de custo alto, o controle dos estímulos relevantes fica atenuado, como ocorre em uma operação abolidora (Michael, 1993). Assim, outros estímulos adquirem maior poder de evocação de respostas alternativas, e tornam mais provável que o sujeito mude o curso de ação e fique sob controle de reforçadores mais imediatos, engajando-se, dessa forma, na classe de respostas classificada como procrastinação. Reduzir a quantidade de resposta, reduz o seu custo e também as pausas pós reforço entre os elos da cadeia comportamental se tornam menores, reduzindo os riscos de que o indivíduo venha a procrastinar suas tarefas essenciais. 
Princípio 6: Enfatize as atividades que são naturalmente agradáveis e fortalecedoras. Atividades estas as quais vocês provavelmente estarão mais propensos a repetir.

Começar por atividades costumeiras é um excelente ponto de partida. Dessa maneira, acrescentar outras atividades que sejam próximas a estas dentro de sua rotina se torna um processo mais fácil.

Principio 7: Atue como um treinador (Você também pode se imaginar em um jogo. Para vencer as fases, que seriam os dias, você precisaria desenvolver novas habilidades).

Estabelecer metas diárias realistas, ainda que discretas, pode ser uma forma de preparar para desenvolver uma rotina proativa e agradável. Uma pessoa pode ter interesse em aprender um idioma novo. Assim uma de suas metas iniciais pode ser selecionar o material que vai ler, ou entrar em contato com um professor que dê aulas on-line ou ainda procurar por aplicativos no celular que ajudem com a pronúncia. Listar as atividades, atribuir um nível de dificuldade em executar cada etapa pode estabelecer um roteiro, como em um jogo no qual um personagem progride entre os níveis conforme as habilidades que vai desenvolvendo.

Princípio 8: Não avalie preconceituosamente algo dizendo que não pode fazer ou que não daria conta. Primeiro tente, caso não dê certo, isso te orientará para uma nova rota de ação.

Uma possível forma pela qual as pessoas se esquivam de fazer uma determinada atividade é antecipadamente dizer que não são capazes de fazê-la. Contudo, é a experiência que pode melhor orientar se conseguem ou não. Expor-se a tentar é um grande começo. Mesmo que uma dada tarefa não seja avaliada como perfeita em seu resultado, é preciso considerar que ao iniciar algo se cria a oportunidade do aprimoramento.

Principio 9: Não apenas fale, faça!

As mudanças não ocorrem em função das promessas, mas da ação. Para tanto é preciso garantir que o curso da ação se mantenha, de maneira que a pessoa atinja as suas metas e sinta-se gratificado por isso.

Princípio 10: Resolver possíveis e reais barreiras à ativação.

A execução de algumas atividades pode ser atrapalhada por alguma eventual dificuldade. Uma pessoa que queira exercitar-se em casa pode se sentir desanimada por não ter os halteres, barras e anilhas à disposição como era na academia. Entretanto, ela pode resolver esse empecilho improvisando pesos caseiros feitos com garrafas pet. Pode ser que alguém esteja com dificuldade de ter um espaço com um pouco mais de privacidade dentro de casa para poder se exercitar. Nesse caso, ela terá que informar aos demais membros da casa sobre sua necessidade de espaço dentro de um período de tempo para cumprir essa atividade.

\section{CONSIDERAÇÕES FINAIS}

A disponibilização de dicas de atividades para a estruturação de novas rotinas durante o período de quarentena e isolamento social é fundamental para minimizar os impactos psicológicos negativos decorrentes dessas tão necessárias medidas sanitárias para retardar a propagação da COVID-19. Nesse sentido, os princípios de Ativação Comportamental podem ser utilizados para orientar a estruturação dessas rotinas. A apresentação simples, clara e objetiva feita virtualmente em um site como o demonstrado neste artigo apresenta sugestões de atividades que podem atingir beneficamente a um grande número de pessoas, estendendo os potenciais benefícios desse recurso terapêutico na prevenção dos danos psicológicos. Além disso, aumenta a chance de que o controle do "ficar em casa" se dê por operações envolvendo reforçamento positivo e não apenas por esquivas de situações aversivas, aumentando o engajamento na manutenção das pessoas em suas casas.

\section{DECLARAÇÃO DE CONFLITO DE INTERESSES}

Os autores declaram que não há conflito de interesses relativos à publicação deste artigo.

\section{CONTRIBUIÇÃO DE CADA AUTOR}

Certificamos que todos os autores participaram suficientemente do trabalho para tornar pública sua responsabilidade pelo conteúdo. A contribuição de cada autor pode ser atribuída como se segue: Gotti, E. S. contribuiu para a concepção do site, organização dos grupos etários e domínios de atividade, adaptação dos princípios de Ativação Comportamental. Argondizzi, J. G. F., Fazolino, N. E. L., Santos, M. D. e Silva, J. L. contribuíram com a escrita sobre os domínios de atividades pensando para diferentes grupos e sobre a discussão dos dados do site com a literatura. Oliveira, E. A. contribuiu no levantamento da literatura. Banaco, R. A. contribuiu com a escrita sobre Ativação Comportamental e com os modelos experimentais de estresse, além de contribuir com a redação final.

\section{DIREITOS AUTORAIS}

Este é um artigo aberto e pode ser reproduzido livremente, distribuído, transmitido ou modificado, por qualquer pessoa desde que usado sem fins comerciais. $\mathrm{O}$ trabalho é disponibilizado sob a licença Creative Commons 4.0 BY-NC.

\section{$(\mathrm{cc}) \overline{\mathrm{BY}-\mathrm{NC}}$}

\section{REFERÊNCIAS}

Banaco, R. A., Zamignani, D. R., Costa, C. E., \& Dantas, M. R. (2015). Modelos Experimentais de depressão. Em E. C. A. Neto, A. C. C. P. Bittencourt, N. B. Araripe, \& M. E. Rodrigues. (Org.). Depressão: Psicopatologia e Terapia Analítico-Comportamental (2ed., pp. 35-54). Curitiba: Juruá Editora.

Beck, A. T. (1967). Depression. Philadelphia: University of Pennsylvania Press.

Brooks, S. K., Webster, R., Smith, L. E., Woodland, L., Wessely, S., \& Greenberg, N. (2020). The psychological impact of quarantine and how to reduce it: rapid review of the evidence. The Lancet, 395 (10227) 912-920. doi: 10.1016/S0140-6736(20)30460-8 
Catania, C. (1999). Aprendizagem: comportamento, linguagem e cognição. Porto Alegre: Artmed.

Cavalcante, S. N. (1997). Notas sobre o fenômeno depressão a partir de uma perspectiva analíticocomportamental. Psicologia: ciência e profissão, 17 (2), 2-12. doi: 10.1590/S1414-98931997000200002

Dahne, J., Lejuez, C. W., Kustanowitz, J., Felton, J. W., Diaz, V. A., Players, M. S., \& Carpenter, M. J. (2017). Moodivate: A self-help behavioral activation mobile app for utilization in primary-care - Development and clinical considerations. International Journal of Psychiatry Medicine, $52 \quad$ (2) 160-175. doi: 10.1177/0091217417720899

Ferreira, D. C., \& Tourinho, E. Z. (2013). Desamparo aprendido e incontrolabilidade: relevância para uma abordagem analítico-comportamental da depressão. Psicologia: Teoria e Pesquisa, 29(2), 211- 219.

Ferster, C. B. (1973). A Functional analysis of depression. American Psychologist, 28, 857-870.

Ferster, C. B., Culbertson, S., \& Perrot-Boren, M. C. (1982). Princípios do Comportamento. São Paulo: Hucitec.

Holmes, E. A., O’Connor, R. C., Perry, V. H., Tracey, I., Wessley, S., Arseneault, L., ... Bullmore, E. (2020). Multidisciplinary research priorities for the COVID-19 pandemic: a call for action for mental health science. The Lancet, 15, 1-14. doi: 10.1016/S22150366(20)30168-1.

Huremovic, D. (2019). Psychiatry of Pandemics: a mental health response to infection outbreak. North Shore University Hospital Manhasset, New York, USA: Springer.

Kanter, J. W., Busch, A. M., \& Rusch, L. (2009). Behavioral activation: distintive features. New York: Routledge Taylor \& Francis Group.

Kanter, J. W., Manos, R. C., Bowe, W. M., Baruch, D. E., Busch, A. M., \& Rusch, L. C. (2010). What is behavioral activation?: A review of the empirical literature. Clinical Psychology Review, 30(6), 608-620 doi: 10.1016/j.cpr.2010.04.001

Lazzari, C., Egan, S. J., \& Rees, C. S. (2011). Behavioral activation treatment for depression in older adults delivered via videoconferencing: A pilot study. Cognitive and Behavioral Practice, 18 (4), 555-565. doi: 10.1016/j.cbpra.2010.11.009

Lewinsohn, P. M., \& Graf, M. (1973). Pleasant activities and depression. Journal of Consulting and Clinical Psychology, 41, 261-268. doi: 10.1037/h0035142
Martell, C. R., Dimidjian, S., \& Hermann-Dunn, R. (2010). Behavioral activation for depression: a clinician's guide. New York: The Guilford Press.

Michael, J. (1993). Establishing operations. The Behavior Analyst, 16 (2), 191-206.

Mikulas, W. L. (1977). Técnica de modificação do comportamento. São Paulo: Harper \& Row do Brasil. doi: 10.1007/BF03392623

Moreira, M. B., \& Medeiros, C. A. (2019). Principios básicos de Análise do Comportamento. Porto Alegre: Artmed.

Oliveira, A. C. F. (2009). Estresse moderado crônico: efeitos sobre a atividade geral em ratos (Tese de Doutorado). Universidade de Brasília, Brasília.

Pero, V., \& Stefanelli, V. (2015). A questão da mobilidade urbana nas metrópoles brasileiras. Revista de Economia Contemporânea (19) 3, 366-402. doi: $10.1590 / 198055271932$

Rajkumar, R. P. (2020). COVID-19 and mental health: a review of the existing literature. Asian Journal Psychiatry, $52 \quad$ (102066) doi: 10.1016/j.ajp.2020.102066

Sidman, M. (2006). Fred S. Keller, um reforçador condicionado generalizado. Revista Brasileira de Análise do Comportamento, 2 (2), 277 - 285. doi: 10.18542/rebac.v2i2.817 .

Skinner, B. F., \& Vaughan, M. E. (1985). Viva bem a velhice. São Paulo: Summus.

Stein, A. T., Carl, E., Cuijpers, P., Karyotaki, E., \& Smits, J. A. J. (2020). Looking beyond depression: a metaanalysis of the effects of behavioral activation on depression, anxiety, and activation. Psychological Medicine, 6, 1- 14. doi: 10.1017/S0033291720000239

Thomaz, C. R. C. (2001). O efeito da submissão ao Chronic Mild Stress (CMS) sobre o valor reforçador do estímulo (Dissertação de Mestrado). Pontifícia Universidade Católica de São Paulo, São Paulo.

Willner, P., Towell, D., Sampson, S., Sophoklcous, S., \& Muscat, R. (1987). Reduction of sucrose preference by chronic unpredictable mild stress, and its restoration by a tricyclic anti depressant. Psychopharmacology, 93, 358-364.

Submetido em: 20/05/2020 Aceito em: 08/07/2020 